\title{
Green groups and grey areas: scientific boundary-work, nongovernmental organisations, and environmental knowledge
}

\author{
Sally Eden $\uparrow$ \\ Department of Geography, University of Hull, Cottingham Road, Hull HU6 7RX, England; \\ e-mail: s.e.eden@hull.ac.uk
}

\section{Andrew Donaldson}

Centre for Rural Economy, University of Newcastle, Newcastle upon Tyne NE1 7RU, England; e-mail: andrew.donaldson@ncl.ac.uk

\section{Gordon Walker}

Department of Geography, Lancaster Environment Centre, Lancaster University, Lancaster LA1 4YB, England; e-mail: g.p.walker@1ancaster.ac.uk

Received 18 August 2004; in revised form 7 February 2005

\begin{abstract}
In this paper we examine the role of nongovernmental organisations (NGOs) in debates about environmental science and knowledge, using empirical evidence from in-depth interviews with a range of NGOs involved in the waste debate in the United Kingdom. We discuss theoretical issues of scientific boundary-work and the construction of expertise and socially distributed knowledge, and then apply these to our empirical evidence. Our conclusions are that NGOs continue to subscribe to the notion of the preeminent authority of science in environmental debates, but also work partly in a more diverse, highly networked world of knowledge production which requires them to be pragmatic and versatile in how they legitimate knowledge from various sources. Hence, scientific knowledge is highly contingent in its authority, and dependent upon continual (re)negotiation.
\end{abstract}

\section{Introduction}

Environmental governance currently involves a diverse range of stakeholders, making it more complicated and contentious to decide how to legitimate the environmental knowledge and contributions of very different groups. Such problems are grist to the mill of sociologies of science (for example, Irwin and Michael, 2003). Researchers have debated the notion of 'lay' expertise, the credibility of scientific 'experts', and how the 'lay-expert divide' is drawn, policed, and challenged (Epstein, 1995; Irwin, 1995; Irwin and Wynne, 1996). But there are less-clearly polarised forms of expertise that have been relatively neglected by analysts, such as those of nongovernmental organisations (NGOs) involved in environmental governance. Under conditions of 'socially distributed knowledge' (Gibbons et al, 1994), NGOs can both produce and consume science, as well as acting as brokers for environmental information and scientific credibility. But science can be an uncertain ally for environmentalists and their expertise can be questioned, as Yearley's $(1989 ; 1991 ; 1996)$ work has shown.

In this paper, we analyse NGOs by considering their activities as scientific actors, redressing the more common emphasis upon their activities as political actors or as part of social movements and countering the relative neglect of NGOs in the sociology of science literature (Epstein, 1995; Jamison, 1996). This focus matters because political and scientific action are differently legitimated. Mass-membership NGOs [like Friends of the Earth, the World Wildlife Fund (WWF), Greenpeace, the Women's Environmental Network] often claim political legitimacy by way of public representation-although this can be heartily contested-because a membership in the thousands arguably implies representation of at least some of the public interest. This is a quite different validation criterion to that of

๑ Corresponding author. 
scientific societies and trade associations which represent (and protect) specific interests; such scientific legitimation may be less easily obtained by NGOs. We first discuss theoretical interpretations of scientific authority and credibility and how NGOs have figured in debates over the changing sociology and politics of scientific knowledge. Using empirical evidence, we then examine how these interpretations play out in the daily practices and perceptions of a variety of NGOs involved in the field of waste science and policy. We particularly consider how relevant and useful are notions of boundary-work and socially distributed knowledge in conceptualising the role of NGOs in the production, distribution, and use of environmental science and knowledge in contemporary debates.

\section{Boundary-work, knowledge production, and NGOs}

"The role of social movements in cognitive change has tended to be ignored by students of social movements as well as by students of science and technology. It is as if knowledge production only becomes interesting for science studies when it has become professionalised and entered the confines of authorised knowledge-producing institutions."

Jamison (1996, page 238)

Jamison's argument highlights the focus of sociologies of science upon science narrowly defined. We argue that, as science spills out of its classical niche and into society more widely, it is appropriate to consider new areas where science, and society's response to science, is both substantively and theoretically significant. The case of NGOs is interesting not least because there is little work that considers NGOs as scientific actors, with the honourable exception of Yearley's work (for example, Yearley $1989 ; 1991 ; 1992 ; 1993 ; 1996)$. But in the public domain, NGOs have frequently been characterised as antiscience, with varying degrees of hostility from self-identified scientific critics or, often, industrial commentators. One example is from a writer in New Scientist, described simply as an "industrial chemist", who wrote, in response to Wynne and Mayer's (1993) call in the same journal for more open, 'greener' science:

"The Greenpeace approach is not anti-science... but neither is it science. So what is it? It is moral philosophy at least, and religion probably. All that scientists can say to Greenpeace is: sorry, your application for membership of the scientific community has been carefully considered - and rejected" (Milne, 1993, page 27).

Such views were compounded by the Brent Spar episode across Europe [see quotations in Huxham and Sumner (1999); and general criticism by Jordan (2001)] and illustrate a general point about the perceived location of environmental NGOs outside 'proper' science. We can analyse this using the concept of boundary-work, which Gieryn $(1983 ; 1995 ; 1999)$ has used to show how scientists have demarcated their professional practices and credentials from other forms of social activity, building and reinforcing boundaries around 'science' and gaining legitimacy and influence. The particular features of 'science' and 'nonscience' to be emphasised differ according to what boundary-work is being done (Gieryn, 1983, pages 785-787). So, 'science' is a resource to be adapted to make the strongest possible rhetorical case: sometimes the boundary of 'science' is drawn very conservatively, and sometimes much more extensively, to suit the agenda of those doing the drawing (Jasanoff, 1987).

Although researchers have commonly seen boundary-work as a fairly strategic and deliberate practice, it may be far less so, becoming normalised or unreflexively routinised within daily scientific and professional practice, as Kinchy and Kleinman (2003) note. Over time, with familiarity and accumulation, the constructions of scientific authority may be 'naturalised' (Gieryn, 1983, page 782), so that science's authority is no longer seen publicly as constructed, but as immanent and therefore less challengeable (if at all). Hence, the construction work is obscured or forgotten: 
"the repeated drawing of boundaries along similar lines across time reflects the historically resonant, and consequently, taken-for-granted character of the discourses on which actors draw" (Kinchy and Kleinman, 2003, page 871).

Hence, boundaries are dualistically built exclusionary devices - and this is precisely their appeal to those involved in contentious debates or competing for finite resources such as public support. Consequently, boundaries differ depending upon the opposition - they are contingently produced and, thus, it is problematic to transfer the type of 'work' done (or authority gained) from one context to another-which is a problem both for theoretical generalisation and for practical transfer of expertise between topics. Moreover, boundaries may not be accepted where boundary work fails to convince. Finally, whilst a useful geographical metaphor, it is important not to reify the boundary but to recognise that it is always shifting and unstable, dependent upon continual renegotiation - the 'naturalisation' of which Gieryn speaks is problematic in times of public distrust and acknowledged scientific uncertainty, such as now. The boundary is more properly seen as a fuzzy zone of negotiation and rhetoric - a grey area which may, moreover, be very different for different issues. For example, the boundaries of legitimate debate around human cloning are quite different to those about GM foods, not least in recognising ethics and precedents as valid platforms for decisionmaking. Indeed, given the dangers of reification, it is better to focus upon the 'work' than the 'boundary'.

Boundary-work is hence "a rhetorical form well suited to the seizure, monopolization, and protection of those goodies" like power, authority, expertise, prestige, and funding (Gieryn, 1995, page 440). The need for work therefore becomes most significant where those goodies are under attack, for example, where science is uncertain but highly important for social survival, as in climate change (Shackley and Wynne, 1996) and BSE (Irwin, 1995), and very publicly discussed. Hence, we should "take the boundaries themselves as entry points for inquiry into the relations between science and power, to ask how they come about, and what functions they serve in channeling both knowledge and politics" (Jasanoff, 2003a, page 394). Those who lose such boundary disputes, those who are demarcated as 'nonscientific' and lacking in the proper expertise and authority, also lose influence and access to those political and cultural resources gained by science (Gieryn, 1983, page 784). As Jasanoff (1987) has shown, boundary-work is also about retaining control and autonomy, especially for scientists and industrialists.

Hence, boundary-work that attempts to cast environmental NGOs (or anyone else, for that matter) as nonscientific may thus undermine their credibility in policy debates. However, today, as noted above, previously naturalised boundaries of expertise are becoming increasingly contested and contingent. This has been theorised particularly as part of a democratisation of science. Beck in his $(1992 ; 1995)$ Risk Society thesis and Functowicz and Ravetz (1990) with their 'second-order science' theory all argue that once the scientific monopoly on rationality is thus broken, knowledge sources begin to multiply to compensate and a dialectic of expertise and counterexpertise is set in motion: science expands and diversifies as other scientists enter the fray (Eden, 1996). Reflexive scientisation may then occur: critics of the results of science use scientific techniques to research and argue their cases, as we increasingly see in environmental and health lobbies. This turns the groups that once merely used science into 'active co-producers' of science in the midst of heterogeneous scientific interpretations (Beck, 1992, page 157). Similar broad arguments are made by Gibbons et al (1994), who argued that, alongside the classical, homogeneous, disciplinary-focused science of 'Mode 1' knowledge production, a supplementary 'Mode 2' is developing which is broader and transdisciplinary, as numerous and more differentiated knowledge 
producers generate knowledge which is contextualised, useful, and socially accountable rather than just true. These arguments are not about having less science nor are they in favour of antiscience, but they are about science spilling out of its classical contexts because these cannot handle complex, transdisciplinary problems, and about society dealing with science in new ways.

Academics have supported this spilling out, making normative appeals for science and expertise to be opened up and democratised (Jasanoff, 2003b), for a 'greener' form of science which would be open and self-critical (Wynne and Mayer, 1993), for 'participatory expertise' as a conscious part of the pluralisation of knowledge (Fischer, 1990), and for an 'extended peer community' (Functowicz and Ravetz, 1990). These arguments are not antiscience but challenges to improve science, because 'extended' expertise selfconsciously challenges the narrowness of traditional science. Thus, changing the conditions of the relationship of science with society involves attempting to emancipate society from science through science, by using counterscientific and alternative arguments in the extended debate (Beck, 1992; Functowicz and Ravetz, 1990). But the problem in such grand arguments comes in delimiting such 'extended expertise'. If we deconstruct the lay-expert boundary and reject the idea that 'scientists' are more qualified to speak on any scientific issue than 'the public', does that mean that everybody is now an expert and a free-for-all ensues? This was Collins and Evans's (2002) concern when they called for 'a normative theory of expertise', which would legitimate 'interactional expertise', where a person has enough expertise to interact with others (real experts) in the field, and 'contributory expertise', where a person has enough expertise to contribute to science in the field (a typical criterion for PhD work, for example). We would argue that, like Turner (2001), Collins and Evans do not extend expertise very far, by sticking too closely to classical notions of science, although they do make the useful point that the boundary of expertise "is no longer between the class of professional accredited experts and the rest; it is between groups of specialists and the rest" (Collins and Evans, 2002, page 270)

But how shall we accredit the new 'specialists', particularly when they are increasingly heterogeneous (for example, Epstein, 1995)? Jamison (2001) argued that social movements, such as environmentalism, have historically provided a context for challenging the dominant forms of knowledge production and interests, and thus for 'reconstituting knowledge', by rejecting science's exploitation of nature and developing collective and participatory forms of learning and a "network-based, project-driven, transdisciplinary mode of knowledge production" (Jamison, 2001, page 68). Can we usefully conceptualise NGOs as reflexive scientific specialists and diverse knowledgeproducers in a climate of more democratic science? Grolin (1998, page 219) certainly saw the Brent Spar episode in the 1990s as illustrating "a shift from the dominance of techno-scientific rationality to a broader and morally based common-sense rationality reflecting the increasing reflexivity and questioning of the authority of science", not least given the successful cultural politics of Greenpeace. But, as we shall later argue, outside contextual episodes, it is harder to argue for a generic shift because authority and legitimation may well remain issue specific for NGOs and difficult to transfer or generalise between issues: expertise "is not so much found as made" in context (Jasanoff, 2003b, page 159, emphasis in original).

However, science has clearly become more important in the work of environmental NGOs. Eyerman and Jamison (1989, page 114) examined the instrumental use of knowledge by Greenpeace International professionals, who were not experts but "intelligencers, environmentalist agents ... hybrid between a professional scientist and a movement activist, not so much producing 'science for the people' as producing intelligence: strategic information for the people.” Since then, the environmental movement 
has sought respectability through professionalisation (Jamison, 2001), commercialisation (Jordan and Maloney, 1997), specialisation, and the development and occupation of knowledge niches, even hiring staff on the basis of their professional expertise (Jamison, 2001). However, specialist responsibilities are not static and may shift within or between NGOs with the issues, in line with Mode 2 above.

Environmental NGOs can also fund 'advocacy science' wherein "experts are hired by competing groups to undermine each other's arguments" (Horlick-Jones and de Marchi, 1995, page 139), becoming customers in the new market for environmental knowledge. Some NGOs may conduct environmental consultancy themselves (Yearley, 1993; 1996), both producing and selling knowledge. The commercialisation of knowledge production is both the cause and the effect of the heterogeneity in knowledge producers already described, evident in the rising influence of consultants and business in environmental debates, although we unfortunately have little room here to consider the potentially interesting economy of this new knowledge market.

\section{Bringing evidence to bear: researching NGOs and science}

We now turn to our empirical evidence to evaluate how far these notions work in practice and to contribute to a literature that is poorly served by empirical work, especially once it moves away from headline-grabbing controversies. Our empirical analysis is based upon twenty-one semistructured, in-depth interviews with NGOs based in the United Kingdom in the field of waste, conducted in 2003. We focused upon waste in order to narrow down our sample and because, unlike more glamorous environmental issues such as genetically modified (GM) crops and climate change, waste has been little regarded by sociologies of science. Yet the United Kingdom has seen regulatory, economic, and structural changes in the field of waste, as well as contested scientific and technological evidence about landfill health risks, incineration risks and sites, pollution from waste, life-cycle assessment methodologies, recycling and composting techniques, hazardous-waste disposal, ecoefficiency, and waste minimisation. We began by interviewing NGOs known to be lobbying and campaigning on waste management and then used member-defined 'snowball' sampling to contact additional groups. We often interviewed two people in large or complicated organisations, to address any concerns about how representative a single individual might be of the wider organisation, even if they were clearly identified as its waste 'specialist'. We asked interviewees about their production and use of environmental science and about their background. Interviews were audiotaped and then fully transcribed before being analysed with grounded theory (systematic coding to saturation).

A distinctive strength of our work is that we symmetrically analysed groups involved in the same waste debates from different 'sides' of the traditional business environmentalist dichotomy. Hence, we interviewed UK staff in the well-known 'environmentalist' NGOs like Greenpeace, Friends of the Earth, and WWF and less well-known 'environmentalist' NGOs like the Green Alliance, the Women's Environmental Network, Forum for the Future, and the National Society for Clean Air. We also conducted interviews with business-related NGOs like the Environmental Services Association, Business in the Environment, the Industry Council for Packaging and the Environment, and the Paper Federation, whose members are companies (although the organisations themselves are often not-for-profit), as well as professional organisations like the Chartered Institution of Waste Management and more difficult-to-categorise groups like the Environment Council, Waste Watch, SWAP, and the Resource Recovery Forum (some of which are not-for-profit consultancies and some of which have diverse memberships and audiences). The business - environmentalist dichotomy is further 
complicated by the business-like organisation of many large environmentalist NGOs today (Jamison, 2001; Jordan and Maloney, 1997) and business outreach and collaborative programmes developed by NGOs of all types to influence business thinking and operations. We want to focus in this paper upon NGOs' scientific strategies and practice, rather than their ideologies or interests. To promote symmetrical comparisons rather than simplistic essentialisms and to avoid the difficulties of categorising some groups, we will refer to them all simply as 'NGOs', as indeed do the UN, which has classified business pressure groups as NGOs for some time. We note this explicitly because we have frequently been asked during presentations of this research how we can justify calling business groups 'NGOs' and because we wish to stress that environmental lobbying is now extremely diverse and difficult to categorise. Our empirical work is therefore particularly rich because it involves a diversity of NGO types, sizes, and orientations. We have anonymised the interview quotations in the interests of confidentiality, distinguishing different organisations by letters and interviewees within the same organisation by numbers.

\section{Legitimacy, science, and NGOs}

Yearley (1991, page 38) has argued that "scientific expertise remains the principal form of legitimation in the leading environmental organisations ... there are no viable alternatives." Despite the arguments above for changing the conditions of knowledge production since Yearley wrote this, scientific expertise is still a highly important form of legitimation in environmental debates. Other forms, such as moral expertise, have not yet become central, unlike in other debates such as those over human cloning and stem cell research. In our interviews, NGOs confirmed Yearley's (1991; 1993; 1996) emphasis upon the importance of scientific legitimacy for their arguments and were at pains to stress their own rationality and use of science.

"We don't want to go out and do something unless there is a very clear science, technically reliable basis to it, if you like" (large environmentalist NGO-Q).

"[Our organisation] has a reputation for well-thought-through, scientifically credible advice" (small environmentalist NGO-K).

We do not seek to essentialise 'science' in this analysis. Indeed, we asked all our interviewees to define 'science' in their own words - a question which provoked very diverse responses and some hesitancy. Our interest is rather in how the NGOs used, legitimated, and discussed 'science' (however defined) in their particular work, because:

"Science is a kind of spatial 'marker' for cognitive authority, empty until its insides get filled and its borders drawn amidst context-bound negotiations over who and what is 'science"" (Gieryn 1995, page 405, emphasis in original).

NGOs' claims to scientific credibility, especially from more environmentalist NGOs, were often rather defensive. For example, one interviewee emphasised the need to build and actively protect a reputation for research rigour, a perceived rationality which needed to be defended independently of political advocacy and argument:

"[Our organisation] has a reputation as being rigorous with its work. Part of our power, part of our strength, is that we articulate it very well, but they know that if we say [something], we get the figures right, we get the analysis right. They may disagree with us over arguments and we can argue over it, but that is very, very important to us that we protect the reputation of our research as being rigorous really and our arguments as being the same. That runs through the work we do in house" (large environmentalist NGO-G). 
Business groups similarly emphasised the need to base their activities on sound science, but acknowledged that they could not as readily claim the independence from commercial interests that underpinned the reputation for rigour that environmental groups sought to construct. As one interviewee commented:

"We're too close to the industry to be totally independent. We are independent, because we're managed independently, but the perception is clearly that we're allied with the industry" (waste association-E).

On the other hand, through their specialist understanding of particular areas of business activity, such NGOs could claim other forms of what we call 'experiential expertise'. For example, a research approach typical of business organisations, especially trade associations, is to "go directly to the horse's mouth" (waste association-B): to collate (environmental) data and experience from member companies, aggregate it to protect commercial confidentiality and release it into the public domain in their own reports. No doubt Turner (2001) and Collins and Evans (2002) would view this disparagingly, because it could be seen as not producing knowledge in the classical scientific sense, but it does generate knowledge that does not otherwise exist or circulate. For such NGOs, this could still provide an important legitimacy in influencing policy:

"It's not very often that we meet Government officials without at least one or two members. Particularly from the large companies; there's a certain amount of credibility in being able to say 'this is our experience and this our insight and these are the problems we're facing and these are the issues we have, and we need guidance or we need help or we need this changed" (waste association-D).

Although legitimacy in the use of knowledge was therefore claimed in different ways, the need for scientific understanding and competence featured across all of the NGOs. All bar four of our twenty-one interviewees had scientific qualifications, with first degrees in chemistry, physics, geology, ecology, environmental management, and similar subjects, and most also had Masters and/or PhDs in fields like environmental management, waste technology, and environmental technology, appropriate to their waste specialism and reflecting professional scientific training, as also found in conservation NGOs by Yearley (1993). Although the more business-oriented interviewees had, unsurprisingly, stronger technical backgrounds in business operations, often after decades of operational management, there was no great divide between our business and environmentalist interviewees in terms of scientific training. Despite this scientific background, our interviewees often saw science as a group or sect that was closed to outsiders, such as themselves, and thus not 'democratic'. In this sense, boundaries clearly were perceived between 'pure' science and NGO work. Science was seen as the 'primary' producer of original knowledge and, in this sense, the work of our NGOs might be scientific but it was not strictly science because it was not 'original'. When asked if they considered themselves and their organisations 'scientific', most interviewees found this difficult to answer definitively and frequently considered that their own and their organisation's background might qualify as 'scientific' whereas the everyday work was less so-a good example of contextualised knowledge. This is because they did 'secondary research' and 'interpretation of science' (not merely reproducing but reanalysing information and evidence), which brought into play their scientific abilities and judgments.

"I am what could be derogatorily described as a 'Xerox Warrior': I work on on-paper desk studies, using and marshalling information that's been dug from the actual scientific work generated elsewhere (large environmentalist NGO-I, 1).

"We don't do the research ourselves, we try and assess which bits of evidence are relevant to the debate" (small environmentalist $\mathrm{NGO}-\mathrm{H}$ ). 
As well as the separation of 'pure' science from NGO policy work, we had also expected to find evidence of boundary-work between NGOs. Where scientific authority is a political resource - one of the 'goodies' of which Gieryn wrote-being inside the boundary of scientific authority should make a group's arguments about policy and technological options more legitimate and influential than those of their opponents. For example, Eden (1999) argued that business lobbies sought to claim legitimacy for their environmental arguments through rationality, which allowed them to cast their environmentalist opponents into the wasteland of irrationality. This is a good example of constructing a 'cartography of credibility' (Gieryn, 1999) that enhances the business groups' authority to speak to policymakers more than their opponents. Jasanoff (1987, page 216) has also shown how industry has sought to define decisions as 'science' and not 'policy', because 'science' was seen to be more favourable to industrial interests. Yet, there were fewer and less vitriolic claims like this in our interviews than we had expected. One interviewee from a trade association did discuss this at length, claiming that "our arguments are based on sound science" (and 'theirs' are not) and arguing that:

"There are all these green lobbies claiming that incinerators are bad for health, cause cancer and kill babies and all that sort of thing, so we need to rely on scientific facts and data as much as we can to counteract that. What we counter the claims with have to be factual... they use a lot of emotional arguments; it's very difficult to try and engage the public in facts" (waste association-D).

Other business-oriented groups did not make such arguments - rather, they pointed to their collaborative working arrangements with other environmentalist NGOs. Commenting from 'inside' the boundary, one interviewee from a large environmentalist NGO emphasised the differentiation between parts of industry and between a public rhetoric of conflict and a private practice of collaboration. Some classic proscienceantiscience oppositional boundary-work may therefore reflect insufficient constructive interaction between certain industrial sectors and environmentalist groups:

"As far as the industry goes, some parts of industry, at least the ones that don't engage so much with [us] on a communications basis, believe that we have no interest in science, that we don't base any of our campaigns or our information on sound science, and that we're somehow antiscience... So there's a fracture between what they say in public and what they actually, what they really perceive. But I've no doubt that some sections of industry, those that we haven't had a close relationship [with], ([which could be] either a positive relationship or a negative one but where we've got to know each other over the years) some sections of industry that don't engage with us will no doubt see us as totally unscientific" (large environmentalist NGO-I, 2).

It might also reflect the unsophisticated expectations of the media as to what environmental politics is like and how far business and environmentalists are perpetually and irrevocably at loggerheads. For example, an interviewee from a waste association (B) told us about how a radio-programme presenter invited her to speak in a head-to-head with an environmentalist-NGO representative and was disappointed at their frequent agreement on air.

We would argue that this dichotomy in rationality has been blurred by very public scientific problems, from BSE to Brent Spar, in the United Kingdom in the 1990s, illustrating the contingent, and possibly unstable, nature of environmental authority. As Irwin and Michael (2003) note, the late 1990s saw a shift even in UK government thinking 'from deficit to dialogue' in terms of public engagement over scientific issues, and companies have similarly been drawn more towards scientific and environmental dialogue. Moreover, as noted above, each NGO draws its own boundaries within the 
NGO sector as to which other NGOs were legitimate. Most commonly, Greenpeace is metaphorically beyond the pale, whereas groups like Forum for the Future, the Green Alliance, and the WWF are firmly inside the pale, especially according to the more business-oriented groups. So, there may be one set of negotiations in public and another in private, typical of the multiplicity of alliances in the contemporary environmental lobby and of the grey area around the boundary.

\section{Context, knowledge production, and quality control}

Beyond such boundary-work, what matters for NGOs is the context in which knowledge is applied:

"Science tells you some things about the world, those then have to be put in the context of people in order for them to make sense" (large environmentalist NGO-Q, 1).

We argue that NGOs partially reflect Mode 2 knowledge production (Gibbons et al, 1994), in the sense that they seek for knowledge to be (a) socially accountable and (b) practically useful in environmental governance. For NGOs science is restricted precisely because, although useful as a source of legitimation because of its supposed neutrality, this neutrality seeks to avoid morals, ethics, judgments, and choices. Here there are some divisions by NGO 'type', because the socially accountable argument was most commonly made by interviewees from environmentalist NGOs, particularly Greenpeace and the WWF.

"If everyone's a scientist that's working on an issue, there is a danger of becoming too involved in the technical aspects of it, and losing the moral clarity, if you like. The further you go into specialised focuses and the technical details of an issue, the further you move away from the simple black-and-white, right-andwrong issue that the public see. And that's what really motivates [our] work. What we're trying to do is retain that perspective of what is actually right and what is actually wrong. I don't think many people in [this NGO] would disagree with me when I say that science doesn't make those decisions, science informs the decisions, but the decision that's what's right and wrong is a political and moral one" (large environmentalist NGO-I, 2).

Moreover, policy has excluded nonscientific elements from many environmental debates on an issue-specific basis, as noted by Yearley (1996). Science is thus at the core of environmental measurement but the NGOs are concerned not with the niceties of science but with its interpretation and consequences.

"If you talked about cloning it was all about the ethics, if you talked about GM crops, the idea that you could have an ethical discussion about it was regarded as like talking about death: it was to talk about something that was unspeakable, that was taboo-you can't really have a conversation about it, it's not valid, it's not acceptable" (large environmentalist NGO-I, 1).

By comparison, the practically useful argument commonly came from the more business-oriented NGOs. The best knowledge was practical or useful in applying science technologically, and cost-effectively, in other contexts, in other words, transferable beyond the context of its production. NGOs frequently saw academics as failing to realise the need for relevance and purifying their own scientific endeavour (and potentially missing out on useful funding sources and alliances in commercial research and development). Academics and research councils were seen as interested in "true research, blue sky, kind of long term, very innovative kind of work", whereas industrial representatives were interested in research that was faster and directly addressing a particular issue (waste association-E).

"If it will only work in a test tube then it's not much good on a practical level" (small community-oriented group- $\mathrm{N}, 1$ ). 
The boundary-work of science versus policy is thus highly contingent and politically charged (Jasanoff, 1987). Moreover, as well as using contextualised knowledge from other sources, NGOs have increasingly sought to produce the kind of policy-relevant knowledge that 'pure' science is failing to produce for them. One example is the laboratory for Greenpeace International, based at the University of Exeter, England. This is the only lab to be affiliated directly with Greenpeace and to undertake scientific analyses on commission for Greenpeace (as well as for other customers), and is thus expanding and diversifying knowledge production. This is unusual - in general, NGOs are highly dependent upon the original research of others (also Yearley, 1993, page 70) and upon bodies which control information release, such as the government or its agencies, or companies which retain data claiming commercial confidentiality. Where NGOs are using science from diverse sources, this raises issues of quality control and validation of expertise-key arguments in the debates about democratising science and opening up knowledge production under Mode 2 expertise - and, with the dismantling of the automatic validation of 'pure' science, there is a fear of free-for-all by some (for example, Collins and Evans, 2002). As Jasanoff (2003a, pages 392-393; similarly Rip, 2003, page 420) argued, expertise is "always contingent, historically situated, and grounded in practice... acquired, and deployed, within particular historical, political, and cultural contexts", and should be conceptualised as such.

"Those who exert quality control in Mode 2 have learned to use multiple criteria not only in general, but in relation to the specific results produced by the particular configuration of researchers involved" (Gibbons et al, 1994, page 34).

Mode 1 knowledge production is typically validated by scientific peer review. The legitimatory perils of failing peer review were demonstrated by the work of Árpád Pustzai et al on rats' consumption of GM potatoes (compare http://www.royalsoc.ac.uk/ gmplants/ and http://www.freenetpages.co.uk/hp/a.pusztai/), although passing through peer review does not necessarily guarantee easy acceptance [as in the controversy over peer-reviewed papers in Climate Research (see Kinne, 2003; also Wall Street Journal 31 July 2003, page A3)]. Leaving aside the arguments over peer review per se, it is clear that NGOs see peer-reviewed science published in academic journals as the gold standard of legitimation, providing "a degree of rigour in the way that that's done" (waste association-L).

"I'd have more faith in something that's been published in an academic journal and less faith in something that's been published by an NGO [laughs]. Probably" (small environmentalist $\mathrm{NGO}-\mathrm{F}, 1)$.

"If it's been peer reviewed in a respectable journal and then open to critique, response, then you have to take it seriously.' (large environmentalist NGO-I, 2).

But even peer-reviewed science can fail the utility test. NGOs are precariously balancing scientific rigour against utility [see Kinchy and Kleinman (2003) on neutrality versus utility in ecological science]. Similarly, Yearley (1996, page 187; also 1993, page 69) notes how conservation NGOs displayed an 'epistemological flexibility' in using science and criticisms of science in their arguments, in a "pragmatic balance between accepting and denying the overriding validity of science" depending on the context. In the context of environmental debates, the expertise of NGOs and their knowledge suppliers is likewise highly contingent-but also diverse, highly networked, and often dependent upon 'face-work' (Giddens, 1990) as much as boundary-work. The old norms of peer-reviewed, closed-off, and abstract science may thus be insufficient for Mode 2 knowledge workers. 
"I also don't believe just because a paper is published and peer-reviewed, I don't believe it's always correct, conclusions or the information in it" (large environmentalist $\mathrm{NGO}-\mathrm{I}, 2$ ).

If the old norms do not work, new ones are needed-but are they creditable and defendable? Quality control is a problem for NGOs under Mode 2, as established legitimating structures, such as peer review, can fail to work (Gibbons et al, 1994, page 32). In interviews we had diverse, lengthy discussions about specific cases of commissioning or collaborating upon a piece of research, although these often concluded that there was no easy way to judge quality or to articulate that judgment.

"I think when it comes down to it, people will recognise good science" (waste association-E).

Hence, beyond the gold standard of peer-reviewed papers, much of NGOs' quality control has become less boundary-work and more face-work, networking through contacts and reputations, and judging by source - "reputational issues of the organisation that's doing the work" (small environmentalist $\mathrm{NGO}-\mathrm{H}$ ) - rather than by content or prepublication peer reviewing, because source indicates organisational interests and agendas:

"The overall institutional attitude is a very good surrogate for where you think, or how much you think that base of knowledge is going to be-not wrong, not wrong in detail, not incorrect - but geared towards certain outcomes that would be favourable to their standpoint. Now in order to make those judgments about what you think is credible and what isn't, then for each issue you need a kind of institutional map of where you're coming from" (large environmentalist NGO-I, 1).

"If it's a university department or a local authority or a consultancy that I know, I will tend to value it higher" (small umbrella NGO-M).

NGOs have also developed their own internal practices of peer review as a form of quality control, whether formalised, as in the refereeing of papers for publication in their in-house journal, or simply through the use of in-house 'experts' on internal scientific or technical committees to review drafts of publications.

"I send out my own work sometimes, to people. Normally other academics who've worked in the field.... So we tend to try and send it to somebody - it might be somebody internal and somebody external if they'll do it for us - and they'll tend to just whip through and come back" (large environmentalist $\mathrm{NGO}-\mathrm{G}$ ).

Jasanoff (1987, page 218) noted how diverse processes of external and internal review were used in the regulatory process in the United States, with the aim "that the discipline of peer review will help hold governmental science to the same standards as science practised outside government" and give it similarly high authority. The parallels with NGOs are clear, are they similarly define peer review in fluid and politically charged ways. However, even peer reviewing may not work for their own credibility, particularly for well-known NGOs like Greenpeace and Friends of the Earth. Interviewees felt that even publishing or citing peer-reviewed papers will not necessarily validate their arguments in the eyes of their critics because they would forever be automatically cast on "that side of the divide" (large environmentalist NGO-G). Sometimes external institutions can be used as a proxy for peer review, through the 'rubber-stamping' of evidence and techniques by government agencies like the Environment Agency in England and Wales that act as "government benchmarking of whether something's good science or bad science" (waste association-B). Given the difficulties in establishing effective reviewing procedures with which everyone will agree, Jasanoff (1987, page 223) was certainly right to note that peer review in such contexts "may remain a contestable concept for the foreseeable future." 


\section{Producing green and grey knowledge}

As noted above, our interviewees felt sometimes that they were criticised because they were too close to industry or too environmentalist. Both are threats to the classical discourse of scientific neutrality that is important in boundary-work (Kinchy and Kleinman, 2003). Where independence of their own organisation is thus insufficient or undermined, NGOs may commission research from another knowledge producer to 'buy in' independence and legitimation.

"[Consultants provide] information which is unequivocal, or as unequivocal as possible, or at least as unbiased as possible. So what we didn't want in our work is that a person could pick it up and say 'well they would say that, wouldn't they, they're an NGO'” (large environmentalist NGO-Q, 1).

"There's always a risk of course that if somebody has a rabid view which opposes what we're saying, they read a report that we say is independent, that they will say as you said 'Well, [you] paid for it'. Well, sure, but how else do we get it done? We could do it ourselves and they'd say the same thing, we could use the company data and they'd say the same thing. At least this [using consultants] gives as much of an element of credibility as you can get" (trade association-L).

Commissioning new knowledge brings NGOs and their suppliers into the knowledge market, linking a wide variety of often specialised knowledge producers and brokers, some of which are private, commercial operators (for-profit consultancies), some less commercially orientated but still in need of funding (not-for-profit consultancies, think-tanks, pressure groups, associations, and individual academics).

"We will go out of house for more substantial bits of research or when we need skills and knowledge that aren't available, which is, I would argue, becoming more common for us to do that than to try and do it in-house" (large environmentalist NGO-I, 1).

"We would go outside for things where we either don't have access to the data, or we don't have expertise to collect or analyse it... we went last year and again this year to an energy consultant to provide hard, independent data on the current economics of running a combined heat and power plant" (trade association-L).

Where research has been commissioned, the amount, specificity, and complexity depend on the size and skills of the NGOs. Highly technical research, particularly running tried-and-tested models of anything from carbon emissions to econometrics, was seen as requiring specialised skills and thus out-sourced. For small NGOs in particular, not only did they not have the skills but they did not have the staff to produce such knowledge - buying in research was a way of buying in people-time. For NGOs, the United Kingdom's Landfill Tax Credits Scheme was originally a boon, diverting some of the new landfill tax to 'Environmental Bodies' and through them to projects related to waste. Several NGOs which specialised in waste were registered as Environmental Bodies and distributed funding for research into wastemanagement problems and solutions. However, for many NGOs, the high cost of commissioning research against small budgets meant that commissioning new work was done in a reactive and purposeful way, not a strategic and general one.

"Say it's in a planning inquiry, say the Government's about to make a decision about regulation, we know that they're getting to the critical phase. And we're saying 'it's significant' and they're saying 'no it's not' .... We need something that's new that actually goes a stage further in proving to them the need" (large environmentalist $\mathrm{NGO}-\mathrm{G})$.

"We produce and use research randomly, opportunistically, and/or if we can make some money out of it" (small environmentalist NGO-K). 
Hence, academic and business consultants were used to guarantee academic independence, rigour, and transparency, producing reports which could "stand up to questioning and elements of peer reviewing" (large environmentalist $\mathrm{NGO}-\mathrm{Q}, 2$ ). A variety of consultants are increasingly important in producing, judging, and circulating knowledge in policy debates, an area often referred to as 'grey literature', reflecting its unclear status and provenance and, frequently, its ephemeral existence. Although academics and peer-reviewed journals were the gold standard, as discussed above, the everyday practice was to turn to consultancies, often cited by name and including the consultancy arms of other NGOs such as the Green Alliance and Waste Watch.

"There's a lot of sort of independent consultants who are quite good. They're almost sort of NGO, yeah, honorary NGOs in the way that they work. But they're trained economists or... they're trained and they've got a history in environmental and economic consultancy" (small environmentalist $\mathrm{NGO}-\mathrm{H}$ ).

"It gives it a little bit, well, a lot of credibility to say 'here is a respected independent consultant, we paid for it, sure, but we paid for their time, this is the report they've given us and this is therefore their conclusions." (trade association-L)

Both individual academics and consultants were chosen because of "member recommendation as much as anything" (waste association-J) but also because of general reputation, personal contact, and familiarity, reflecting the routinisation of contacts. This applied to both business-oriented and environmentalist groups, who commissioned research on the basis of:

"reputation, networking and seeing stuff they've produced in the past... there's no objective criteria; it's sort of seat of the pants, really" (small environmentalist $\mathrm{NGO}-\mathrm{K}$ ), and

“a history of respectability, they've got a track record ... years' worth of data behind them" (large environmentalist $\mathrm{NGO}-\mathrm{Q}, 2$ ).

Surprisingly, there is little academic work about environmental consultanciesfurther marking it as a 'grey area'-because, although important knowledge-generators and distributors, they are low-profile. The focus in most sociologies of science on science qua science is thus neglecting a host of potentially influential knowledge producers.

\section{Conclusions}

It is clear that science still forms the main legitimation for environmental argumentsit remains "singly authoritative" (Yearley, 1993, page 71) under the Mode 1 model of homogeneous, disciplinary-focused knowledge production and expertise, despite Gibbons et al's (1994) arguments. However, we have shown that NGOs are increasingly networking in a Mode 2 model of more numerous and differentiated knowledge producers in which expertise is to an extent democratised and knowledge is contextualised and above all made useful. Classical, peer-reviewed science can be a powerful ally for NGOs because of its supposed neutrality and legitimacy, and NGOs are consequently concerned to build and protect a reputation for using such 'sound science' and being rigorous in the evidence they use to inform argument and advocacy. But we have found that NGOs are typically pragmatic and versatile in their use of legitimation: where it is useful, they draw on classical notions of expertise and where it is not they begin to develop and legitimate their own. They balance classical scientific rigour against utility; adopt an epistemological flexibility in using and being critical of science, as Yearley (1996) suggested; find alternative methods of peer review and validation; and draw on a diversity of knowledge suppliers. Such a highly networked environment is not an easy one in which to work or indeed to research. Much of what takes place is reliant on the grey areas of working practices, personal contact, 
familiarity, and networks that are rarely explicit and formalised to any significant degree.

Our empirical evidence supports and exemplifies the theoretical literature regarding both the diversification of expertise and socially distributed knowledge and the challenges thereby implied. However, we would problematise the easy theorisation and categorisation of this diversity. In the environmental field, we would argue that NGOs are key actors in the democratisation of expertise and useful knowledge, but will not necessarily and consistently contribute to what, for some, are normative goals. Challenging Mode 1 boundary-work through 'reconstituting knowledge' (Jamison, 2001, page 46) would contribute to the democratisation of environmental science but, in many contexts, accepting and playing along with existing rules might make NGOs more influential in policy debates. NGOs are therefore not simply the unswerving proponents of Mode 2 that some theorists would like, but also perpetuate Mode 1 when it suits the issue and their stance. Similarly, we have shown that environmental and business NGOs are not simply differentiated into oppositional camps. In practice, they communicate and cooperate around scientific issues in more productive ways, but they will also resort at times to classical boundary-work to score points and achieve policy influence through casting the opposite lobby as antiscientific or unscientific and using knowledge which is outside the boundary of credibility. They are pragmatists rather than theoretical purists. As we noted above, they are not merely scientific actors, because their use of science is but one aspect of their character - and a highly contextualised one at that.

What are the implications of this for theoretical development? Boundary-work, we would argue, is still useful as a way of conceptualising contestation within environmental governance, but needs to be seen as a fuzzy or grey zone which may be very different for different issues. In this sense, we concur with Kinchy and Kleinman (2003) that much boundary-work and many challenges are not strategic but contextual, sometimes routinised, but also highly tactical and adaptable. Moreover, expertise built around one boundary does not automatically transfer to another. The relationship of NGOs with science does not simplistically reflect the academic calls noted above for a greener, more democratic science, not least because NGOs tactically both deploy and neglect such challenges.

Focusing upon the 'work' of boundary-work has stressed to us that analysis must be issue based, dealing with 'episodes' of boundary-work as an important part of subpolitics, rather than being able to generalise about authority in an effective way. Similarly, the democratisation of environmental knowledge discussed earlier emphasises continual (re)negotiation and public involvement in contingent and unstable ways. We therefore offer no simple prescriptions for legitimating or including diverse forms of environmental knowledge in conflictual debates and argue against Collins and Evans's (2002) search for a normative theory of expertise on the grounds of rigidity. Moreover, we have only been able to skate over the grey area of consultancy - which is clearly highly important in policy debates but highly neglected by academic work. There is still plenty left to do. More research on the NGO-science interaction would help us to compare examples of boundary-work and the construction of expertise in different times and places and also on different environmental issues. It would also help us to be cautious about theoretically interpreting the role of NGOs as the vanguard of scientific democratisation. But it also illustrates how NGOs are inventing new ways to generate and legitimate knowledge and are adapting some elements of classical science to their own purposes. In particular, their use of 'peer review', in which not scientists but other NGOs and interested academics review their reports, borrows classical ideas but redefines the notion of 'peers' to mean those 
with relevant expertise, whether academic scientists or not. Such collective, negotiated, and heterogeneous knowledge production and validation is thus not merely about extending notions of expertise but extending ways of working across, within, and outside science - policy boundaries.

Acknowledgements. In this paper we report on work conducted under the Economic and Social Research Council's Science in Society Programme, award number L144250047, "Contesting Environmental Science: Business and Environmentalist NGOs". We thank audiences at conferences of the Association of American Geographers and the European Sociological Association for their comments on presentations of this work and, most of all, the participants in our interviews, from whom we have learnt so much.

\section{References}

Beck U, 1992 Risk Society (Sage, London)

Beck U, 1995 Ecological Politics in an Age of Risk (Polity, London)

Collins H M, Evans R, 2002, "The third wave of science studies" Social Studies of Science 32 $235-296$

Eden S, 1996, "Public participation in environmental policy: considering scientific, counter-scientific and non-scientific contributions" Public Understanding of Science 5 183-204

Eden S, 1999, " "We have the facts'-how business claims legitimacy in the environmental debate" Environment and Planning A 31 1295-1309

Epstein S, 1995, "The construction of lay expertise: AIDS activism and the forging of credibility in the reform of clinical trials" Science Technology and Human Values 20408 - 437

Eyerman R, Jamison A, 1989, "Environmental knowledge as an organizational weapon: the case of Greenpeace" Social Science Information $2899-119$

Fischer F, 1990 Technocracy and the Politics of Expertise (Sage, Thousand Oaks, CA)

Functowicz S O, Ravetz J R, 1990 Global Environmental Issues and the Emergence of Second Order Science Report EUR 12803 EN (Commission of the European Communities, Luxembourg)

Gibbons M, Limoges C, Nowotny H, Schwartzman S, Scott P, Trow M, 1994 The New Production of Knowledge (Sage, London)

Giddens A, 1990 The Consequences of Modernity (Polity, Cambridge)

Gieryn T, 1983, "Boundary-work and the demarcation of science from non-science: strains and interests in professional ideologies of scientists" American Sociological Review 48781 - 795

Gieryn T, 1995, "Boundaries of science", in Handbook of Science and Technology Studies Eds S Jasanoff, G E Markle, J C Petersen, T Pinch (Sage, London) pp 393-444

Gieryn T, 1999 Cultural Boundaries of Science: Credibility on the Line (University of Chicago Press, Chicago, IL)

Grolin J, 1998, "Corporate legitimacy in risk society: the case of Brent Spar” Business Strategy and the Environment $7213-222$

Horlick-Jones T, de Marchi B, 1995, "The crisis of scientific expertise in fin de siècle Europe" Science and Public Policy $22139-145$

Huxham M, Sumner D, 1999, "Emotion, science and rationality: the case of the Brent Spar" Environmental Values 8349 - 368

Irwin A, 1995 Citizen Science (Routledge, London)

Irwin A, Michael M, 2003 Science, Social Theory and Public Knowledge (Open University Press, Buckingham)

Irwin A, Wynne B (Eds), 1996 Misunderstanding Science? (Cambridge University Press, Cambridge)

Jamison A, 1996, "The shaping of the global environmental agenda: the role of non-governmental organisations", in Risk, Environment and Modernity Eds S Lash, B Szerszynski, B Wynne (Sage, London) pp 224-245

Jamison A, 2001 The Making of Green Knowledge (Cambridge University Press, Cambridge)

Jasanoff S, 1987, "Contested boundaries in policy-relevant science" Social Studies of Science 17 $195-230$

Jasanoff S, 2003a, "Breaking the waves in science studies: comment on H M Collins and Robert

Evans, 'The third wave of science studies'” Social Studies of Science 33389 - 400

Jasanoff S, 2003b, “(No?) Accounting for expertise” Science and Public Policy 30157 - 162

Jordan G, 2001 Shell, Greenpeace and the Brent Spar (Palgrave, Basingstoke, Hants)

Jordan G, Maloney W, 1997 The Protest Business (Manchester University Press, Manchester)

Kinchy A J, Kleinman D L, 2003, "Organizing credibility: discursive and organizational orthodoxy on the borders of ecology and politics" Social Studies of Science 33 869-896 
Kinne O, 2003, "Climate Research: an article unleashed worldwide storms" Climate Research 24 $197-198$

Milne A, 1993, "The perils of green pessimism" New Scientist 12 June, pp 34-37

Rip A, 2003, "Constructing expertise: in a third wave of science studies?" Social Studies of Science $33419-434$

Shackley S, Wynne B, 1996, "Representing uncertainty in global climate change science and policy: boundary-ordering devices and authority" Science, Technology and Human Values 21275 -302

Turner S, 2001, "What is the problem with experts?" Social Studies of Science 31 123-149

Wynne B, Mayer S, 1993, "How science fails the environment" New Scientist 5 June, pp 33 - 35

Yearley S, 1989, "Bog standards: science and conservation at a public inquiry" Social Studies of Science $19421-438$

Yearley S, 1991, "Greens and science: a doomed affair?" New Scientist 13 July, pp 37-40

Yearley S, 1992, "Skills, deals and impartiality: the sale of environmental consultancy skills and public perceptions of scientific neutrality" Social Studies of Science 22 435-453

Yearley S, 1993, "Standing in for nature: the practicalities of environmental organizations' use of science", in Environmentalism: The View from Anthropology Ed. K Milton (Routledge, London) pp $59-72$

Yearley S, 1996, "Nature's advocates: putting science to work in environmental organisations", in Misunderstanding Science? The Public Reconstruction of Science and Technology Eds A Irwin, B Wynne (Cambridge University Press, Cambridge) pp 172 - 190 
Conditions of use. This article may be downloaded from the E\&P website for personal research by members of subscribing organisations. This PDF may not be placed on any website (or other online distribution system) without permission of the publisher. 